\title{
O SISTEMA LINGUÍSTICO COMO SISTEMA ECOLÓGICO: UM ESTUDO DA GRAMÁTICA TETUN (TIMOR-LESTE)
}

\author{
(Linguistic system as ecological system: a study on Tetun \\ grammar - East Timor)
}

Davi Borges de Albuquerque ${ }^{1}$

(Universidade Federal de Sergipe - UFS)

\begin{abstract}
Tetun and Portuguese are the official languages of East Timor. Tetun is an Austronesian language and it is lingua franca in eastern half of Timor Island before the Portuguese colonization, which started in $16^{\text {th }}$ century. This paper intends to present a contribution to ecolinguistic research by mapping ecological and unecological elements on Tetun grammar. Thus, some theoretical issues on ecolinguistic, ecological view of linguistic system and the importance of the identification of ecological and unecological elements will be elaborated. In addition, the ecolinguistic approach will be applied to Tetun linguistic system analysis. This ecolinguistic approach adopted in this paper is also explained. The final remarks on ecolingustic research in East Timor and its contributions will be pointed out as conclusion for this work.

Keywords: ecological elements; unecological elements; Tetun language; East Timor.

\section{RESUMO}

A língua Tetun ${ }^{2}$ é a língua oficial de Timor-Leste, juntamente com a língua portuguesa. O Tetun, de origem austronésia, é a língua franca de

1. Mestre em Linguística na Universidade de Brasília, onde cursa atualmente o doutorado em Linguística, com uma tese sobre a língua portuguesa no contexto da ecologia linguística timorense.

2. Grafias alternativas Tetum, Tétum e Tetun. Optou-se pela grafia Tetun, e para seus compostos também, como tetunófono, assim como Tetun Prasa por estar em proximidade com a ortografia padronizada (que usa s para representar a fricativa alveolar surda /s/) e o sistema fonológico da língua (que não possui $/ \mathrm{m} / \mathrm{em}$ posição de coda silábica).
\end{abstract}


grande parte do território leste-timorense provavelmente desde a época anterior à chegada do colonizador português, no século XVI. O presente artigo possui o objetivo de contribuir para a pesquisa em ecolinguística ao realizar uma tentativa de mapear alguns elementos ecológicos e não ecológicos na gramática da língua Tetun. Assim, na seção (1), serão feitas algumas considerações teóricas sobre a ecolinguística, juntamente com a visão ecológica do sistema linguístico e a importância da identificação dos elementos ecológicos e não ecológicos nas línguas. Na seção (2), será feita a análise do sistema linguístico tetunófono de acordo com a teoria ecolinguística adotada e desenvolvida na seção anterior. Finalmente, em (3), serão apresentadas as considerações finais.

Palavras-chave: elementos ecológicos; elementos não ecológicos; Língua Tetun; Timor-Leste.

\section{Introdução}

Timor é uma pequena ilha localizada no extremo sudeste asiático, próxima à Austrália, ao sul, e às ilhas do Pacífico, a leste. Somente a parte leste da ilha, como já diz o próprio nome do país, República Democrática de Timor-Leste, ou simplesmente Timor-Leste, faz parte do território leste-timorense. A parte oeste é território indonésio.

Devido a sua localização estratégica e a importância de um tipo de madeira, chamado sândalo branco (Santalum album), os povos de Timor estiveram sujeitos a diversos contatos no decorrer da história. Primeiramente, em tempos pré-históricos, ocorreu o contato entre os povos papuásicos, que já habitavam a ilha de Timor, com o povo que realizou a primeira migração austronésica. Este longo contato linguístico entre as línguas austronésicas e papuásicas em Timor foi o fator mais importante para a formação de uma área linguística (Hull, 2001). Em meados do século XIII houve uma segunda migração austronésica, que causou uma série de empréstimos e reestruturação gramatical nas línguas já faladas na ilha. Logo em seguida, no século XV, o contato com os comerciantes de diversas origens étnicas deve ter se realizado com o uso do Pazar Melayu, acelerando o processo de reestruturação gramatical iniciado anteriormente. 
Mapa 1-Timor Leste e suas fronteiras

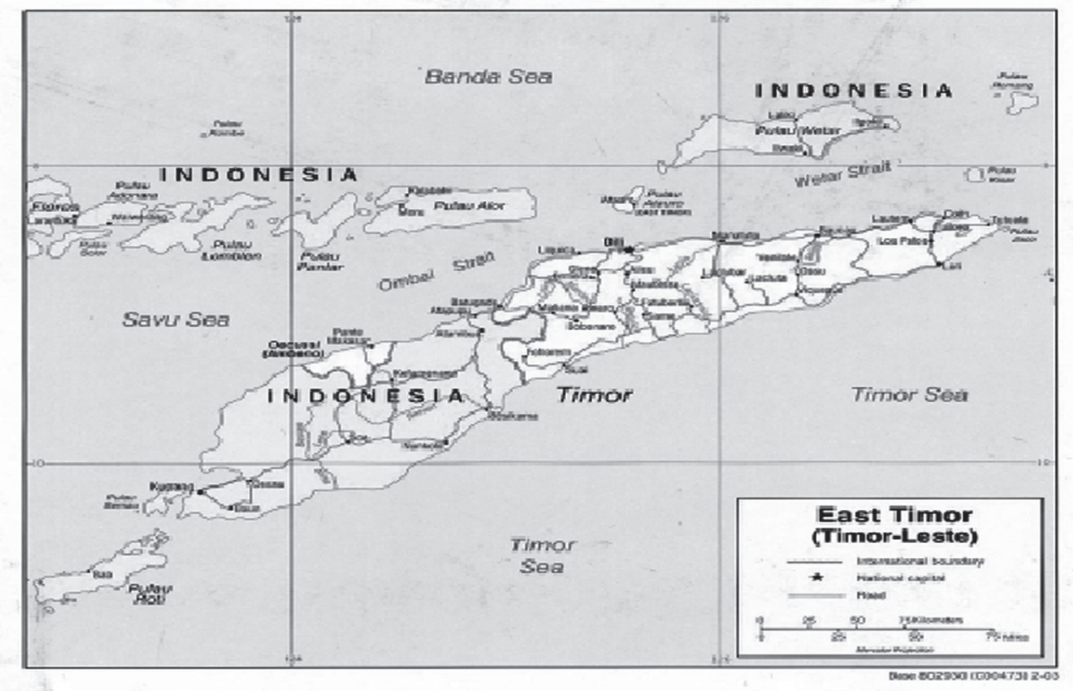

(Fonte: http://www.lib.utexas.edu/maps/middle_east_and_asia/east_timor_pol_03.pdf)

Apesar de os portugueses terem chegado à ilha de Timor no início do século XVI, somente dois séculos mais tarde, em 1702, é que eles vieram efetivamente habitar a ilha, fundando uma capital em Lifau, atual região do enclave de Oecussi. Posteriormente, no ano 1769, ocorreu a mudança da capital de Lifau para Dili, que era uma região falante de Manbae, desencadeando assim mais mudanças linguísticas.

Ainda, além da colonização portuguesa, a ilha de Timor foi invadida pelo Japão de 1942 a 1945, e no ano de 1975 o país sofreu uma dominação da Indonésia que se estendeu até 1999. Após esta invasão indonésia, Timor-Leste precisou se reconstruir e na constituição de 2002, elegeu a língua Portuguesa e Tetun, em sua variedade Tetun Prasa, como línguas oficiais, e a língua inglesa e o bahasa indonesia como línguas de trabalho.

Nos últimos anos, o Tetun Prasa, em sua variedade Tetun Dili, como língua urbana vem recorrendo à língua portuguesa para 
realizar um grande número de empréstimos relativos ao mundo moderno. Vale lembrar que a língua Tetun é de origem Austronésica e funciona como língua franca no território leste-timorense em um período anterior ao século XVII (Thomaz, 2002), provavelmente desde o século XV (Albuquerque, 2009). Há duas principais variedades, a saber: Tetun Prasa e Tetun Terik (Albuquerque, 2011) ${ }^{3}$. O Tetun Prasa se caracteriza pela perda da morfologia flexional, presente no Tetun Terik, que consiste em uma série de sufixos marcadores de pessoa, posse e mudança de valência, dos quais o Tetun Prasa apresenta alguns resquícios somente dos sufixos que modificam a valência. Ainda, o Tetun Prasa apresenta um inventário fonológico e lexical maior do que o Tetun Terik, por causa da influência lusófona sobre aquele. Desta maneira, o Tetun Terik se caracteriza pela retenção de estruturas austronésias, como a rica morfologia flexional, léxico tradicional e empréstimos malaios, e inventário fonológico reduzido.

Os dados foram coletados em momentos distintos, ocorrendo um primeiro período com diversas pesquisas de campo entre os anos de 2008 e 2009, em diferentes localidades de Timor-Leste. Posteriormente, durante o ano de 2010 foram conduzidas várias entrevistas com cidadãos leste-timorenses residentes no Brasil. Ainda, foram consultadas as gramáticas do Tetun Prasa (Albuquerque, 2011; Hull e Eccles, 2001; Williams-van Klinken, Hajek e Nordlinger, 2002).

$\mathrm{O}$ presente artigo possui o objetivo de contribuir para a pesquisa em ecolinguística ao realizar uma tentativa de mapear alguns elementos ecológicos e não ecológicos na gramática da língua Tetun. Assim, na seção (1), serão feitas algumas considerações teóricas sobre a ecolinguística, juntamente com a visão ecológica do sistema linguístico e a importância da identificação dos elementos ecológicos e não ecológicos nas línguas. Na seção (2), será feita a análise do sistema linguístico tetunófono de acordo com a teoria ecolinguística

3. Há certa controvérsia em relação à variação dialetal da língua Tetun. Alguns autores subdividem a variedade Tetun Terik em duas, a saber: Tetun Terik e Tetun Belo, acabando por considerar estas como duas variedades diferentes, aumentando o número para três variedades diferentes. 
adotada e desenvolvida na seção anterior. Finalmente, em (3), serão apresentadas as considerações finais.

\section{Elementos ecológicos e não ecológicos}

Seguindo a tradição de Haugen (1972), que definiu ecolinguística como o estudo das relações entre língua e meio ambiente, outros ecolinguistas acabaram por se utilizar de tal conceito e expandiramno, não o limitando somente ao estudo de uma língua específica dentro de uma sociedade multilíngue, conforme o estudo original de Haugen. Entre esses ecolinguistas, destacam-se: Mühlhäusler (2003), Garner (2004) e Couto (2007).

Sendo o conceito de 'meio ambiente' um dos pilares da ecolinguística, faz-se necessário defini-lo de maneira simples e objetiva, assim 'meio ambiente' é entendido aqui como o lugar onde determinada espécie, ou grupo de espécies, vivem e interagem entre si. Ainda, o meio ambiente é um componente do ecossistema, que é definido como um composto de população de organismos e suas diversas interações entre si e com o respectivo habitat. Calvet (1999) chama atenção para o fato de que tudo na ecologia parte de relações: relações entre células geram organismos pluricelulares, estes, por sua vez, se organizam em colônias ou sociedades, que consideradas em sua totalidade são as populações, as várias populações são classificadas como biocomunidades que integram um biótopo, e o ecossistema consiste no conjunto de biótopos. O linguista expande estas interrelações hierárquicas para a linguística, considerando em sua análise o ecossistema linguístico, o nicho das línguas, o meio ambiente, a regulação, a valência das espécies e a homeostase ${ }^{4}$.

O ecossistema, por ser objeto de estudo da ecologia, é o ponto central dela e, por isso, optou-se por chamar de linguística ecossistêmica o tipo de ecolinguística que considera o ecossistema

4. Os princípios de regulação e homeostase estão interligados na teoria ecolinguística e explicam os processos de adaptação e evolução das línguas. 
como ponto de partida e ponto de chegada da análise realizada, porque tudo na Ecologia emerge do ecossistema ou imerge nele (Couto, 2012a). Outros tópicos que são fundamentais da ecologia (e da linguística ecossistêmica), além da já mencionada interação, são: a diversidade, a abertura ou porosidade, o holismo, a adaptação, o caráter dinâmico (ou a evolução) e a visão de longo prazo ${ }^{5}$.

No presente trabalho, foram identificados os elementos ecológicos e não ecológicos no sistema linguístico Tetun como produtos das interações no ecossistema leste-timorense. Assim, a gramática sofreu evolução e adaptação a diferentes mudanças que ocorreram no meio ambiente linguístico. Ainda, a comunidade de fala tetunófona em que se baseia a presente análise é considerada como um todo, ou seja, são encaradas as formas de inter-relações que ocorrem, e que ocorreram, dentro dela, sendo de fundamental importância para o estudo realizado aqui o conceito de holismo.

Desta maneira, serão apontadas as características básicas de três conceitos fundamentais da linguística ecossistêmica que se encontram nesta análise, são eles: adaptação, evolução e holismo. Após a exposição destes conceitos, será discutida a importância para os estudos ecolinguísticos da identificação dos elementos ecológicos e não ecológicos na gramática das línguas.

A 'adaptação' consiste basicamente nas modificações feitas para a sobrevivência das espécies em relação a mudanças no ecossistema. $\mathrm{Na}$ análise a ser realizada na seção seguinte, apresentar-se-á que as mudanças linguísticas, os empréstimos e a reestruturação gramatical são frutos de adaptação linguística a mudanças que ocorreram no meio ambiente e, consequentemente, alterando também a interação com outras espécies.

A 'evolução' está intimamente ligada ao conceito de 'adaptação'. Segundo a teoria linguística atual, a língua muda constantemente e, caso não tivesse esse caráter dinâmico/evolutivo, seria um instrumento incapaz de saciar as necessidades do falante, já que rapidamente, ou seja, em uma geração ou duas, ela se tornaria obsoleta. Vale lembrar

5. A proposta da linguística ecossistêmica, assim como seus pontos fundamentais expostos aqui, baseou-se em Couto (2012a). 
que o conceito de evolução, já existente na linguística, é apenas considerado como relacionado com os demais conceitos da linguística ecossistêmica, e assume também um lugar proeminente, quando comparado com a teoria tradicional.

O 'holismo' consiste no fato de o investigador delimitar um ecossistema e encará-lo como um todo, estudando uma espécie, ou um espécime, e as inter-relações que esse espécime, ou espécie, mantém no interior de todo o ecossistema (Couto, 2012a). Nash (2011, p. 94) chama isto de minimalismo empírico, usado na escola ecolinguística de Adelaide, Austrália (Mühlhäusler, 2003), e considera o ecossistema uma comunidade de fala reduzida e tangível.

Desde 1990, com Halliday (2001), um tópico importante e presente na ecolinguística é a relação 'holismo x fragmentação'. Para o autor, um tema importante a ser pesquisado é como o sistema linguístico, considerado por ele como a gramática, possui elementos ecológicos e não ecológicos. Ainda, esta contribuição de Halliday (2001) destaca outros temas que devam ser também investigados, são eles: "como encontrar esses elementos ecológicos e não ecológicos nas línguas?", "a língua influencia a visão de mundo, ou vice-versa?", "como medir as influências da língua sobre a visão de mundo? E da visão de mundo sobre a língua?”. Desta maneira, a pesquisa ecolinguística a respeito destes aspectos citados está apenas em estágio inicial e com poucos resultados preliminares a serem apontados. Por isso, Fill (2001) enfatiza que a tarefa da ecolinguística para o século XXI é exatamente investigar essas relações entre língua e meio ambiente, e língua e visão de mundo.

Fill (2001: 65) enumera uma série de elementos não ecológicos, que levam à fragmentação, presentes no sistema linguístico, são eles: separação entre agente, paciente, experienciador, instrumento, entre outros (assim como do alinhamento sintático nominativo-acusativo, e da separação voz ativa/ voz passiva), que separa o ser humano da natureza; categorização de fenômenos em processos ou coisas; separação entre humanos, animais e plantas; sistemas classificadores para as diferentes espécies; a causalidade, que pressupõe controle e superioridade; o sistema pronominal; a marcação de posse; expressões temporais e marcação das categorias TMA, entre outros. 
Essa fragmentação consiste no fato de ocorrer a separação em vários níveis distintos entre o homem e o meio ambiente, e estas separações estarem tanto presentes na visão de mundo, quanto no sistema linguístico, como exemplos: humano $\mathrm{x}$ animais, humano $\mathrm{x}$ seres inanimados, coisas úteis para o ser humano $\mathrm{x}$ coisas não úteis, $\mathrm{e}$ assim por diante.

Digno de nota é a presença do antropocentrismo no sistema linguístico, outro fator considerado como fragmentador por Fill (2001: 67). Porém, como a língua é um sistema de comunicação humana que reflete os limites e possibilidades da cognição humana sempre haverá traços antropológicos nas línguas. Todavia, o antropocentrismo que é considerado como não ecológico, ou seja, fragmentador, é aquele que não apenas percebe o mundo pela visão humana, mas que se utiliza do sistema linguístico para se referir somente ao meio ambiente na medida que este apresenta recursos utilizáveis para o ser humano.

Outro problema com que o pesquisador em ecolinguística se depara é o de como realizar a interpretação dos dados linguísticos, mapeando-os como elementos ecológicos ou não ecológicos dentro de um sistema linguístico específico. Pois de acordo com a análise do sistema linguístico tetunófono, que será realizada na seção seguinte, certos elementos considerados na teoria ecolinguística como não ecológicos podem ser interpretados como ecológicos, já que a gramática, o sistema linguístico, sendo como uma memória dos estágios anteriores da língua (Halliday, 2001), apresenta certos elementos não ecológicos como possíveis frutos de uma adaptação já realizada, ou em andamento, da gramática a alguma modificação no meio ambiente, ou até a um novo meio ambiente.

Finalmente, a ecolinguística distingue duas posturas para o estudo ecológico das línguas, uma que se preocupa com as relações entre as línguas, e as línguas com o meio ambiente, outra que investiga as inter-relações existentes em uma língua. Esta distinção foi elaborada inicialmente por Makkai (1993), que propôs a terminologia de 'linguística exoecológica' para a primeira, e 'linguística endoecológica' para a segunda. Embora não muita 
usada por outros ecolinguistas, o presente autor considera que esta dicotomia é um procedimento metodológico importante para auxiliar o investigador em suas investigações ecolinguísticas, por isso ela será adotada neste trabalho, enfatizando que a análise a ser realizada concentrar-se-á nas inter-relações do sistema linguístico do Tetun, sendo classificada como endoecológica. Ainda, Couto (2007) em sua teoria ecolinguística, juntamente com suas análises, também adota a distinção proposta por Makkai (1993), e Calvet (1999) faz essa mesma separação, porém chama de 'macrolinguística' e 'microlinguística'.

\section{O sistema linguístico Tetun}

Serão analisados nesta seção o funcionamento e a origem de alguns elementos fragmentadores do Tetun, que acabam por tornar certos traços linguísticos como não ecológicos. Por limitações de espaço, questões metodológicas e pelo fato de a pesquisa ecolinguística em Timor-Leste se encontrar em estágio inicial, foram escolhidos somente os seguintes elementos para esta análise: a causalidade, os pronomes pessoais, a marcação de posse, a expressão de tempo e a marcação TMA. A seguir cada um deles será estudado.

\subsection{Causalidade}

A causalidade em Tetun é marcada com o prefixo ha- que é derivado do Proto-Austronésio (PAN) *pa- ou pelo verbo halo 'fazer' em construções com verbos seriais (ing. SVC - serial verb constructions) formadas pelo verbo halo 'fazer' com função causativa mais o verbo principal ${ }^{6}$ :

6. Abreviações utilizadas nos exemplos: ABL 'ablativo', CAU 'causativo', FUT 'futuro', IND 'indefinido', IRR 'irrealis' ITE 'aspecto iterativo', LOC 'locativo', PL 'plural', PON 'aspecto pontual', POS 'possessivo', PROG 'aspecto progressivo', RED 'reduplicação'. 
1. mane nebaa ha-mate reuniaun horisehik homem aquele CAU-morrer reunião ontem 'Aquele homem encerrou a reunião ontem.'

2. tenki ha-manas hahaan atu ema obrevive ter CAU-esquentar comida para pessoa sobreviver 'Deve-se esquentar a comida para as pessoas sobreviverem.'

3. sira halo funu hasoru inimigu baibain. $3 \mathrm{pl}$ fazer guerra contra inimigo dia-RED 'Eles guerrearam contra o inimigo comum'

4. dala ruma malae sira halo viazen ba Bali às.vezes estrangeiro PL fazer viagem para Bali 'Às vezes, os estrangeiros viajam para Bali nas férias.'

A causalidade é interpretada como sendo um elemento não ecológico pelo fato de causar a separação 'homem x natureza', assim como pressupor um controle do ser humano sobre ações, processos e eventos naturais e também sobre outros animais e seres humanos, ou seja, uma superioridade de um ser humano sobre outro, e sobre o meio ambiente. Porém, de acordo com Albuquerque (2011), há uma série de classes verbais no Tetun, e o prefixo causativo somente pode ser empregado em algumas delas, não podendo ser empregue nas demais, como nos verbos de movimento, locomoção, de comunicação, cognição, modais, dêiticos, existenciais, entre outros. Isso mostra que a causalidade em Tetun é limitada a algumas classes verbais, fazendo com que este elemento seja não ecológico somente de maneira parcial, já que o controle do ser humano para causar/controlar as ações, eventos e processos é limitado.

\subsection{Os pronomes pessoais}

Em relação aos pronomes pessoais, de acordo com Mühlhäusler (2003: 19), a escolha de uso deles geralmente não é determinada pela gramática, mas por uma seleção consciente do falante para posicionar/representar a si mesmo em relação ao outro, juntamente com os demais elementos do discurso. Ainda, Couto (2012b) enfatiza diversos problemas na análise dos pronomes, sendo o principal o 
posicionamento tradicional de o pronome ser apenas substituto do nome. Couto (2012b) enfatiza também a importância de se contemplarem todos os atores (reais e/ou potenciais) de uma interação comunicativa.

Desta maneira, a tabela a seguir apresenta o paradigma pronominal tetunófono, juntamente com os atores da interação comunicativa a que os pronomes pessoais fazem referência:

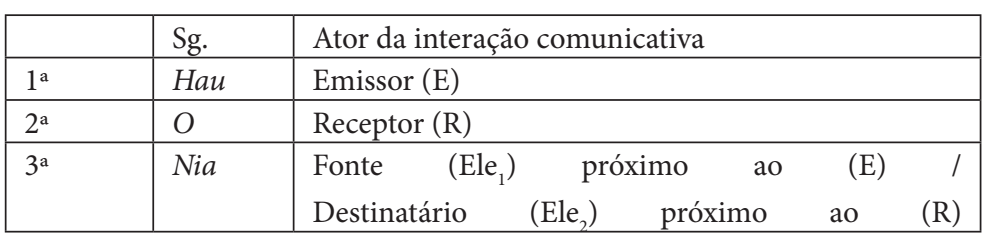

Tabela 1. Paradigma pronominal do Tetun - Singular

\begin{tabular}{|l|l|l|}
\hline & Pl. & Atores da inter. comum. \\
\hline $1^{\mathrm{a}}$ & Ita & $\mathrm{Eu}+\mathrm{tu}$ \\
\hline & $a m i$ & $\mathrm{Eu}+\mathrm{Ele}_{1} / \mathrm{Eu}+\mathrm{Ele}_{2}$ \\
\hline $2^{\mathrm{a}}$ & $i m i$ & $\mathrm{Tu}+\mathrm{Ele}_{1} / \mathrm{tu}+\mathrm{Ele}_{2}$ \\
\hline $3^{\mathrm{a}}$ & sira & $\mathrm{Ele}_{1}+\mathrm{Ele}_{2}$ \\
\hline
\end{tabular}

Tabela 2. Paradigma pronominal do Tetun - Plural

De acordo com as tabelas apresentadas anteriormente, podese facilmente inferir que no desenvolvimento da gramática Tetun, os falantes tetunófonos escolheram expressar gramaticalmente somente os atores da interação comunicativa que foram apontados na tabela. As demais possibilidades existentes, que podem ser várias se contabilizados os atores da interação comunicativa seguindo a análise combinatória, são expressas de outras formas, e não por pronomes. Seguindo a proposta de Couto (2012b), a combinatória de possibilidades de atores da interação comunicativa que podem estar codificados nos pronomes pessoais é infinita, porém nas línguas do mundo somente algumas delas são marcadas por meio de pronomes, enquanto as demais podem não ser marcadas, ou inferidas pelos falantes através do 
contexto discursivo ou situacional. Ainda, há combinações que podem ser marcadas por outras estratégias gramaticais, como locuções, morfologia flexional, morfologia derivacional, como os exemplos que seguem de outras possibilidades que são expressas em Tetun:

5. $\mathrm{Eu}+\mathrm{tu}+\mathrm{Ele}_{1}+\mathrm{Ele}_{2} / \mathrm{Eu}+\mathrm{Ele}_{1}+\mathrm{Ele}_{2}$ ema hotu 'pessoa + todos' / ema sira 'pessoa + PL'

6. $\mathrm{Tu}+\mathrm{Ele}_{1}+\mathrm{Ele}_{2}$ imi sira '2pl + PL' / ita-boot sira 'honorífico + PL'

7. $\mathrm{Ele}_{1 \mathrm{a}}+\mathrm{Ele}_{1 \mathrm{~b}}+\mathrm{Ele}_{1 \mathrm{c}}(\ldots) / \mathrm{Ele}_{2 \mathrm{a}}+\mathrm{Ele}_{2 \mathrm{~b}}+\mathrm{Ele}_{2 \mathrm{c}}(\ldots)$ sira hotu ' $3 \mathrm{pl}+$ todos'

8. $\mathrm{Ele}_{1 \mathrm{a}}+\mathrm{Ele}_{1 \mathrm{~b}}+\mathrm{Ele}_{1 \mathrm{c}}(\ldots)+\mathrm{Ele}_{2 \mathrm{a}}+\mathrm{Ele}_{2 \mathrm{~b}}+\mathrm{Ele}_{2 \mathrm{c}}(\ldots)$ hotu-hotu 'todos RED'

Digno de nota é que a escolha dos pronomes pessoais pelo falante reflete também a posição deste em relação ao meio ambiente e, no caso da língua Tetun, pode ser apontada na referência a $2^{\mathrm{a}}$ e $3^{\mathrm{a}}$ pessoas. O pronome $o$ ' $22^{a}$ pessoa do singular' é usado para se referir somente a crianças, animais pequenos ou para enfatizar o status social alto do emissor. Nos demais casos, omite-se o pronome, substituindo-o pelo nome da pessoa, ou por substantivos que expressam relações de tratamento, como maun 'amigo, colega (faixa etária aproximada)', alin 'irmão mais novo, pessoa do sexo masculino e mais nova', senoor 'senhor'. O pronome nia ' 3 a pessoa do singular' é usado com maior frequência para se referir somente a humanos, enquanto para se referir a animais usa-se o próprio substantivo, como asu 'cachorro', bibi 'cabra', que acabam por ser interpretados respectivamente como 'o cachorro' e 'a cabra' que está sendo referido, e para fenômenos naturais geralmente se emprega o nome ou se omite, quando recuperado no contexto.

Desta maneira, é possível afirmar que, com exceção do pronome hau ' $1^{a}$ pessoa / emissor', os pronomes pessoais em Tetun Prasa são usados para exclusivamente marcar no discurso que o receptor, fonte ou destinatário são não humanos (inanimados ou animais), pois ao se empregá-los para se referir a um dos atores da interação comunicativa, isso é interpretado pelo falante nativo como desrespeitoso, ou ofensivo, 
assim para se realizar a referência/retomada de qualquer um desses atores no discurso faz-se necessário obrigatoriamente mencioná-los por seus nomes (uso de substantivo). Logo, o pronome pessoal em Tetun Prasa pode ser interpretado como um elemento não ecológico, já que possui a função de classificar e separar humano, de um lado, e não humanos, de outro.

\subsection{A marcação de posse}

Segundo Hull (2001), em um estágio anterior da língua havia uma série de sufixos, flexionados de acordo com a pessoa, que marcava a posse. Ainda, havia também o sufixo *-ne que era afixado aos pronomes pessoais para formar um pronome possessivo objeto. Posteriormente, estas marcações gramaticais caíram, sendo substituídas pelo enclítico =nia, do malaio punya 'possuir', que é usado até hoje para formar tanto pronomes possessivos, quanto marcar a posse.

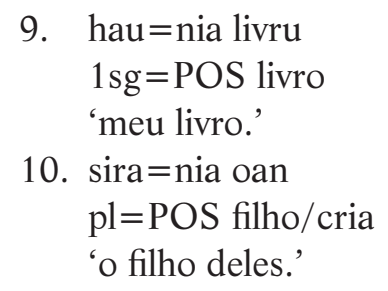

Atualmente, há resquícios da antiga marcação de posse, assim como da distinção de nomes inalienáveis e alienáveis. Os nomes inalienáveis recebiam o sufixo, enquanto os alienáveis não. Por isso, substantivos que eram outrora inalienáveis possuem no estágio atual da língua Tetun um $-n$ final, de acordo com os exemplos a seguir em (11), comparando com os alienáveis em (12) terminados em vogal:

11. ibun 'boca', ain 'perna, pé', aman 'pai', naran 'nome', fatin 'local';

12. mota 'rio', ahi 'fogo', au 'bambu', ai 'madeira', ema 'pessoa', tasi 'mar'. 
Em relação à marcação de posse, argumento aqui que este é um elemento antropocêntrico e também parcialmente ecológico em Tetun, pelo fato de, apesar da posse ser analisada como não ecológica, foi apresentado que este fenômeno gramatical adaptou-se às modificações sofridas no ecossistema, assim como a distinção 'alienável x inalienável' pode ser interpretada como uma consciência ecológica do falante, ao expressar sua capacidade de possuir (diretamente) somente uma parte dos elementos naturais, ou seja, não há controle ou poder por meio da posse por parte do ser humano sobre a natureza e os fenômenos naturais.

\subsection{Expressão de tempo e marcação de TMA}

Segundo Couto (2007: 142), a expressão de tempo, juntamente com a marcação deste, é derivada das expressões espaciais, já que a noção de tempo está ligada a movimento, e movimento é propriedade da matéria (energia). Já Chawla (1991) foi pioneira ao trazer a crítica à noção ocidental de tempo como uma seta (passado $>$ presente $>$ futuro) para a análise linguística. Esta visão, já criticada anteriormente por autores como o físico Albert Einstein, faz com que a sociedade ocidental moderna encare tudo o que é passado como rudimentar, limitado, ruim etc. Isto acaba por deixar de lado outras visões de tempo, como o tempo cíclico ou tempo subjetivo (movimento), que fazem parte de diversas culturas espalhadas pelo mundo.

A expressão de tempo em Tetun não contraria as informações apontadas acima, já que uma parcela das expressões temporais foi formada a partir de expressões espaciais ${ }^{7}$, entre elas:

13. uluk 'primeiro, antigamente', do verbo $u l u-k$ 'estar a frente' e da raiz ulu-n 'cabeça';

7. As demais expressões de tempo em Tetun são marcadas simplesmente por lexemas nativos, como: aban 'amanhã', kalan 'noite', fulan 'mês, lua', ou por empréstimos lusófonos, como agora 'agora', oras nee 'neste momento (nesta hora)', anu 'ano', antiz antes 'antes'. Digno de nota é que os empréstimos lusófonos serviram para introduzir conceitos temporais novos, que eram estranhos à cultura lestetimorense. 
14. ikus 'último, final', da raiz iku-n 'calda';

15. fulan oin mai 'mês que vem, ou próximo mês', de oin 'rosto' e mai 'vir';

16. semana kotuk 'semana passada' de kotuk 'costas, atrás';

17. iha $+(\mathrm{N})+$ nia laran 'durante' de laran 'dentro, coração' nia moras iha fulan rua nia laran. 3 sg doente LOC mês dois 3 sg dentro 'Ele ficou doente durante dois meses.'

Ainda, a noção de tempo do povo tetunófono não era aquela de seta, que procura marcar somente o suposto desenvolvimento acima de tudo, mas por meio do léxico da língua é possível recuperar uma noção de tempo cíclico ligado à época de semeadura e colheita e às amplas estações chuvosas e secas, típicas do clima de monções, que é o clima predominante em Timor-Leste. Assim, há na língua Tetun o lexema bailoron 'estação seca' e udan que significa tanto 'estação de chuva', quanto 'chuva, chover', porém atualmente se encontra com maior frequência o uso da locução tempu udan para se referir a 'estação de chuva'. Outras evidências a respeito da noção de tempo do povo tetunófono que o léxico da língua traz são o conceito de 'dia' e 'mês'. O conceito de 'dia' está ligado ao sol, já que o lexema loro- $n$ 'dia' deriva de loro 'sol', apesar de essa informação não ser reveladora, mostra a importância do sol para este povo. O mesmo ocorre com o conceito de 'mês' que é expresso pelo lexema fulan, porém este mesmo lexema também significa 'lua', apontando que a noção de tempo para esse povo estava também ligada às fases da lua, ou seja, para o povo falante de Tetun a noção e a marcação de tempo estavam relacionadas com o meio ambiente.

Sobre o sistema $\mathrm{TMA}^{8}$ em Tetun, é possível perceber outro fator ecológico já mencionado, que é o da adaptação. Isto é afirmado

8. Considera-se aqui T (tempo), M (modo) e A (aspecto), e a terminologia dessas categorias verbais, juntamente com a proposta de análise presente em Albuquerque (2011, p. 104), foi baseada em Comrie (1976, 1985), Dik (1997), Palmer (2001) e Payne (1997). 
pelo fato de o sistema TMA do Tetun ser formado de maneira semelhante ao das línguas crioulas, com lexemas pré-verbal e pósverbal gramaticalizados (Albuquerque, 2011). Outro fator que leva à noção de adaptação é o fato de que todos os marcadores de TMA são lexemas derivados do malaio, entre eles: telah > tiha 'já', lebih 'mais' $>$ lai 'inicialmente', sih tidak 'ainda não' > seidauk 'ainda não' > dauk $>$ daudauk 'continuamente', masih $>$ sei 'ainda'.

$\mathrm{O}$ fato de esses marcadores verbais em Tetun serem gramaticalizados, estarem em posição anterior ou posterior ao verbo e serem empréstimos do malaio evidencia que provavelmente eles foram inseridos durante o século XV, período citado como de grande influência malaia sobre as línguas de Timor-Leste, fazendo com que entrassem em ação os processos de adaptação e evolução. A adaptação ocorreu pelo fato do Tetun ter que se modificar para conviver com a nova espécie, a língua malaia, inserida no meio ambiente linguístico de Timor-Leste, e consequentemente saber sobreviver às modificações ocorridas no meio ambiente por causa da inserção desta nova espécie. Posteriormente, essa adaptação linguística foi incorporada ao Tetun e passada para as gerações futuras falantes da língua fazendo com que ocorresse naturalmente o processo de evolução do Tetun.

Seguem os exemplos dos marcadores: tiha 'já' que é marcador de aspecto perfectivo, em (18) e (19); lai 'inicialmente' que expressa o aspecto pontual, em (20); daudauk marcador de aspecto progressivo, em (21) e (22); sei 'ainda' que é analisado como marcador de tempo futuro, em (23) e (24):

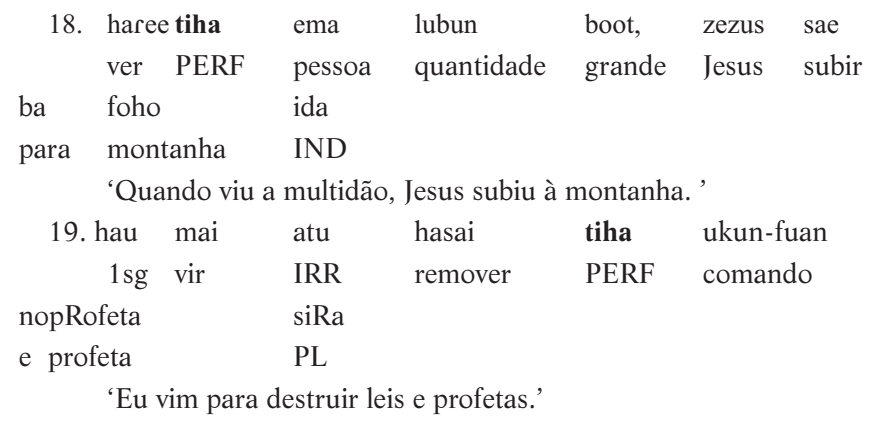


P. 175-194 Davi Borges de Albuquerque

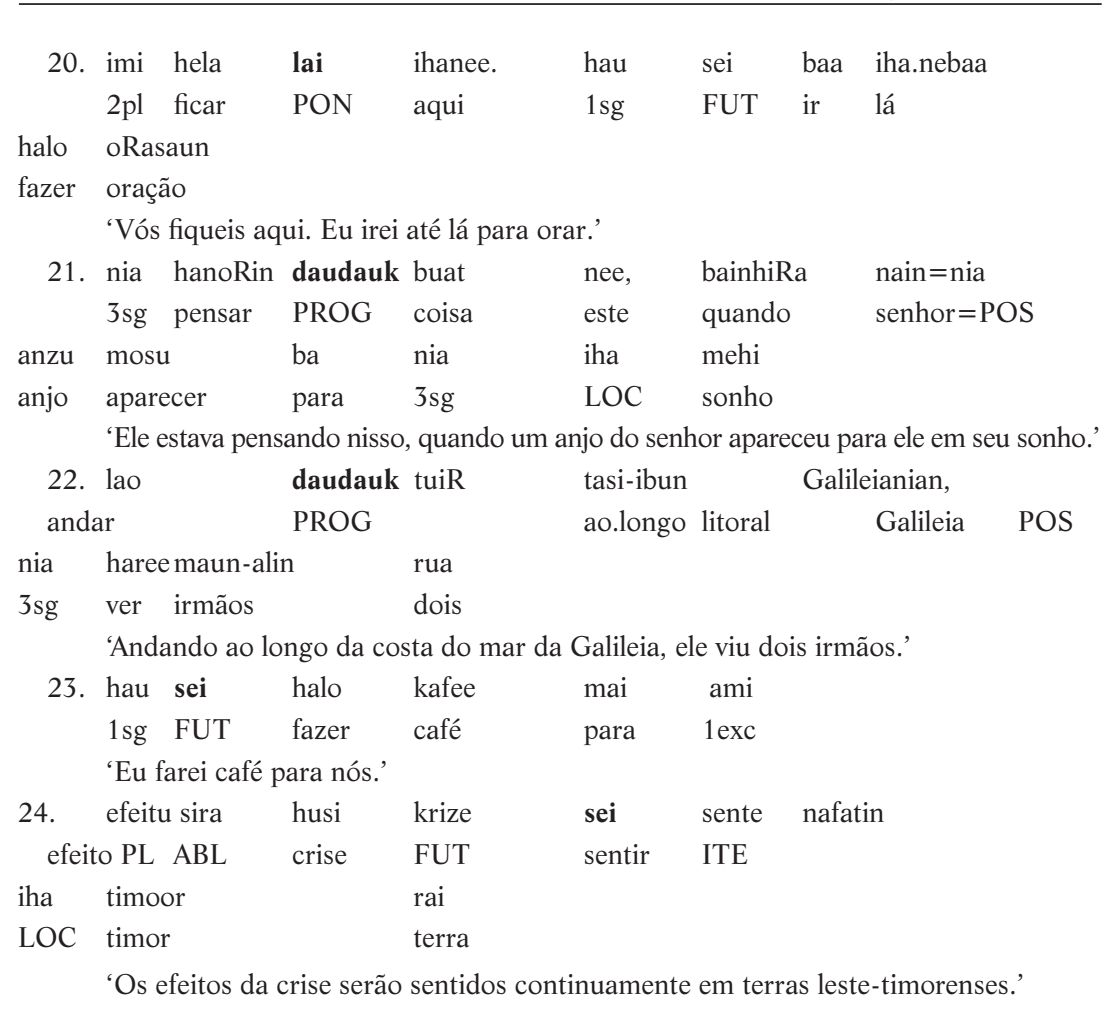

\section{Considerações finais}

Este trabalho analisou os seguintes elementos ecológicos e não ecológicos no sistema linguístico do Tetun: a causalidade, os pronomes pessoais, a marcação de posse, a expressão de tempo e a marcação TMA. De acordo com as evidências apresentadas na análise é que a interpretação desses elementos considerados na teoria ecolinguística como não ecológicos pode ser feita como parcialmente ecológicos, já que a gramática Tetun possui alguns desses elementos como uma memória dos estágios anteriores da língua onde ocorreram sucessivas adaptações a inserções de novas espécies linguísticas, o malaio e o português, que desequilibraram o meio ambiente das línguas de Timor- 
Leste, além de que ocorreu também a mudança de meio ambiente de Lifau para Dili.

De acordo com Fill (2001), entre as tarefas da ecolinguística na atualidade estão: verificar quais são os elementos ecológicos e não ecológicos, como se distribuem e se manifestam nas línguas do mundo, quais são as línguas, áreas e regiões onde esses elementos estão mais presentes. Assim, o presente trabalho teve objetivo de contribuir tanto para os estudos ecolinguísticos, como para um melhor conhecimento sobre as línguas de Timor-Leste, principalmente sobre aspectos da endoecologia linguística da língua Tetun, já que os estudos de ecolinguística de Timor-Leste estão apenas em seu estágio inicial. Desta maneira, espera-se que futuramente a pesquisa ecolinguística em Timor-Leste possa revelar mais aspectos importantes a respeito deste ecossistema linguístico que ainda está por ser estudado.

uma parte dos elementos naturais. capacidade de possuir somente o, e geralmenteRecebido: 25/08/2012

Aceito: $10 / 12 / 2012$

albuquerque07@gmail.com

\section{Referências bibliográficas}

Albuquerque, D. B. Pré-história, história e contato linguístico em Timor Leste. Domínios de Lingu@agem, 6 (2): 75-93, 2009.

Albuquerque, D. B. Esboço gramatical do Tetun Prasa: língua oficial de TimorLeste. Dissertação (Mestrado em Linguística). Programa de Pós-Graduação em Linguística, Universidade de Brasília, Brasília. 2011.

Calvet, J-L. Pour une écologie des langues du monde. Paris: Plon, 1999.

Chawla, S. Linguistic and philosophical roots of our environmental crisis. Environmental Ethics, 13 (3): 253-273, 1991.

Comrie, B. Aspect: An Introduction to the Study of verbal aspect and related problems. Cambridge: Cambridge University Press, 1976. 
Comrie, B. Tense. Cambridge: Cambridge University Press, 1985.

Couto, H. H. Ecolinguística. Estudo das relações entre língua e meio ambiente. Brasília: Thesaurus, 2007.

Couto, H. H. Linguística ecossistêmica. 2012a. Disponível em: http:// meioambienteelinguagem.blogspot.com.br/2012/06/linguisticaecossistemica.html. Acesso em: 26 Jun. 2012.

Couto, H. H. A emergência dos pronomes pessoais na ecologia da interação comunicativa. 2012b. Disponível em: http://meioambienteelinguagem. blogspot.com.br/2012/03/emergencia-dos-pronomes-pessoais-na.html. Acesso: 26/06/2012.

Dik, S. C. The theory of functional grammar. Part 1: The Structure of the clause. Berlin/New York: Mouton de Gruyter, 1997.

Fill, A. Language and ecology: ecolinguistic perspectives for 2000 and beyond. In: Graddol, D. (ed.). AILA Review 14. Applied linguistics for the $21^{\text {st }}$ century. Londres: Catchline, 2001, p. 60-75.

Garner, M. 2004. Language: An Ecological View. Bern: Peter Lang, 2004.

Halliday, M. A. K. New Ways of Meaning: the Challenge to Applied Linguistics. In: Fill, A.; Mühlhäusler, P. (ed.). The ecolinguistics reader. Language, ecology, and environment. Londres: Continuum, 2001, p.175-202.

Haugen, E. The Ecology of language. Stanford: Stanford University Press, 1972.

Hull, G. A Morphological overview of the Timoric Sprachbund. Studies in Languages and Cultures of East Timor, 4: 98-205, 2001.

Hull, G.; Eccles, L. Tetum Reference Grammar. Sydney/Dili: Sebastião Aparício da Silva Project/Instituto Nacional de Linguística/Universidade Nacional de Timor Lorosa'e, 2001.

Makkai, A. Ecolinguistics. ¿Toward a New Paradigm for the Science of Language? Londres: Pinter Publishers Ltd., 1993.

Mühlhäusler, P. Language of environment, environment of language: a course in ecolinguistics. Londres: Battlebridge, 2003.

Nash, J. Norfolk Island, South Pacific: An empirical ecolinguistic case study. Journal of the Australasian Universities Language and Literature Association, 116: 83-97, 2011.

Palmer, F. R. Mood and Modality. Cambridge: Cambridge University Press, 2001. 
Payne, T. E. Describing Morphosyntax. A guide for field linguistics. Cambridge: Cambridge University Press, 1997.

Thomaz, L. F. Babel Loro Sa'e: O Problema Lingüístico de Timor Leste. Lisboa: Instituto Camões, 2002.

Williams-Van Klinken, C.; Hajek, J. e Nordlinger, R. Tetun Dili: A grammar of an East Timorese language. Canberra: Pacific Linguistics, 2002. 